\title{
Coupled best proximity points in ordered metric spaces
}

\author{
P Kumam ${ }^{1}$, V Pragadeeswarar ${ }^{2}$, M Marudai $^{2}$ and K Sitthithakerngkiet ${ }^{3 *}$
}

\author{
"Correspondence: \\ kanokwans@kmutnb.ac.th \\ ${ }^{3}$ Nonlinear Dynamic Analysis \\ Research Center, Department of \\ Mathematics, Faculty of Applied \\ Science, King Mongkut's University \\ of North Bangkok (KMUTNB), \\ Wongsawang, Bangsue, Bangkok, \\ 10800, Thailand \\ Full list of author information is \\ available at the end of the article
}

\begin{abstract}
In this paper, we prove the existence and uniqueness of a coupled best proximity point for mappings satisfying the proximally coupled contraction condition in a complete ordered metric space. Further, our result provides an extension of a result due to Luong and Thuan (Comput. Math. Appl. 62(11):4238-4248, 2011; Nonlinear Anal. 74:983-992, 2011).

MSC: $41 \mathrm{~A} 65 ; 90 \mathrm{C} 30 ; 47 \mathrm{H} 10$

Keywords: partially ordered set; optimal approximate solution; proximally increasing mapping; coupled fixed point; coupled best proximity point
\end{abstract}

\section{Introduction and preliminaries}

Let $A$ be a nonempty subset of a metric space $(X, d)$. A mapping $T: A \rightarrow X$ has a fixed point in $A$ if the fixed point equation $T x=x$ has at least one solution. That is, $x \in A$ is a fixed point of $T$ if $d(x, T x)=0$. If the fixed point equation $T x=x$ does not possess a solution, then $d(x, T x)>0$ for all $x \in A$. In such a situation, it is our aim to find an element $x \in A$ such that $d(x, T x)$ is minimum in some sense. The best approximation theory and best proximity pair theorems are studied in this direction. Here we state the following well-known best approximation theorem due to Ky Fan [1].

Theorem 1.1 ([1]) Let $A$ be a nonempty compact convex subset of a normed linear space $X$ and $T: A \rightarrow X$ be a continuous function. Then there exists $x \in A$ such that $\|x-T x\|=$ $d(T x, A):=\inf \{\|T x-a\|: a \in A\}$.

Such an element $x \in A$ in Theorem 1.1 is called a best approximant of $T$ in $A$. Note that if $x \in A$ is a best approximant, then $\|x-T x\|$ need not be the optimum. Best proximity point theorems have been explored to find sufficient conditions so that the minimization problem $\min _{x \in A}\|x-T x\|$ has at least one solution. To have a concrete lower bound, let us consider two nonempty subsets $A, B$ of a metric space $X$ and a mapping $T: A \rightarrow B$. The natural question is whether one can find an element $x_{0} \in A$ such that $d\left(x_{0}, T x_{0}\right)=\min \{d(x, T x): x \in A\}$. Since $d(x, T x) \geq d(A, B)$, the optimal solution to the problem of minimizing the real valued function $x \rightarrow d(x, T x)$ over the domain $A$ of the mapping $T$ will be the one for which the value $d(A, B)$ is attained. $A$ point $x_{0} \in A$ is called a best proximity point of $T$ if $d\left(x_{0}, T x_{0}\right)=d(A, B)$. Note that if $d(A, B)=0$, then the best proximity point is nothing but a fixed point of $T$. Also, best proximity point theory in ordered metric spaces was first studied in [2].

o2014 Kumam et al: licensee Springer. This is an Open Access article distributed under the terms of the Creative Commons Attribution License (http://creativecommons.org/licenses/by/2.0), which permits unrestricted use, distribution, and reproduction in any medium, provided the original work is properly cited. 
The existence and convergence of best proximity points is an interesting topic of optimization theory which recently attracted the attention of many authors [3-13]. Also one can find the existence of best proximity point in the setting of partially order metric space in [14-17].

On the other hand, Bhaskar and Lakshmikantham have introduced the concept called mixed monotone mapping and proved coupled fixed point theorems for mappings satisfying the mixed monotone property, which is used to investigate a large class of problems, and they discussed the existence and uniqueness of a solution for a periodic boundary value problem. One can find the existence of coupled fixed points in the setting of partially order metric space in [18-24].

Now we recall the definition of a coupled fixed point which was introduced by Sintunavarat and Kumam in [16]. Let $X$ be a nonempty set and $F: X \times X \rightarrow X$ be a given mapping. An element $(x, y) \in X \times X$ is called a coupled fixed point of the mapping $F$ if $F(x, y)=x$ and $F(y, x)=y$.

The authors mentioned above also introduced the notion of mixed monotone mapping. If $(X, \leq)$ is a partially ordered set, the mapping $F$ is said to have the mixed monotone property if

$$
x_{1}, x_{2} \in X, \quad x_{1} \leq x_{2} \quad \Longrightarrow \quad F\left(x_{1}, y\right) \leq F\left(x_{2}, y\right), \quad \forall y \in X
$$

and

$$
y_{1}, y_{2} \in X, \quad y_{1} \leq y_{2} \quad \Longrightarrow \quad F\left(x, y_{1}\right) \geq F\left(x, y_{2}\right), \quad \forall x \in X
$$

In [25] Luong and Thuan obtained a more general result. For this, let $\Phi$ denote all functions $\phi:[0, \infty) \rightarrow[0, \infty)$ which satisfy

(i) $\phi$ is continuous and nondecreasing,

(ii) $\phi(t)=0$ if and only if $t=0$,

(iii) $\phi(t+s) \leq \phi(t)+\phi(s), \forall t, s \in(0, \infty]$.

Again, let $\Psi$ denote all functions $\psi:(0, \infty] \rightarrow(0, \infty]$ which satisfy $\lim _{t \rightarrow r} \psi(t)>0$ for all $r>0$ and $\lim _{t \rightarrow 0^{+}} \psi(t)=0$.

The main theoretical results of Luong and Thuan, in [25] is the following.

Theorem $1.2([25])$ Let $(X, \leq)$ be a partially ordered set and suppose there is a metric $d$ on $X$ such that $(X, d)$ is a complete metric space. Let $F: X \times X \rightarrow X$ be a mapping having the mixed monotone property on $X$ such that

$$
\phi(d(F(x, y), F(u, v))) \leq \frac{1}{2} \phi(d(x, u)+d(y, v))-\psi\left(\frac{d(x, u)+d(y, v)}{2}\right)
$$

for all $x, y, u, v \in X$ with $x \geq u$ and $y \leq v$, where $\psi \in \Psi$ and $\phi \in \Phi$. If there exist $x_{0}, y_{0} \in X$ such that $x_{0} \leq F\left(x_{0}, y_{0}\right)$ and $y_{0} \geq F\left(y_{0}, x_{0}\right)$. Suppose either

(a) $F$ is continuous or

(b) $X$ has the following property:

(i) if a nondecreasing sequence $\left\{x_{n}\right\} \rightarrow x$, then $x_{n} \leq x$ for all $n$,

(ii) if a nonincreasing sequence $\left\{y_{n}\right\} \rightarrow y$, then $y \geq y_{n}$ for all $n$,

then there exist $x, y \in X$ such that $F(x, y)=x$ and $F(y, x)=y$. 
Motivated by the above theorems, we introduce the concept of the proximal mixed monotone property and of a proximally coupled weak $(\psi, \phi)$ contraction on $A$. We also explore the existence and uniqueness of coupled best proximity points in the setting of partially ordered metric spaces. Further, we attempt to give the generalization of Theorem 1.2.

Let $X$ be a nonempty set such that $(X, d)$ is a metric space. Unless otherwise specified, it is assumed throughout this section that $A$ and $B$ are nonempty subsets of the metric space $(X, d)$; the following notions are used subsequently:

$$
\begin{aligned}
& d(A, B):=\inf \{d(x, y): x \in A \text { and } y \in B\}, \\
& A_{0}=\{x \in A: d(x, y)=d(A, B) \text { for some } y \in B\}, \\
& B_{0}=\{y \in B: d(x, y)=d(A, B) \text { for some } x \in A\} .
\end{aligned}
$$

In [9], the authors discussed sufficient conditions which guarantee the nonemptiness of $A_{0}$ and $B_{0}$. Also, in [7], the authors proved that $A_{0}$ is contained in the boundary of $A$. Moreover, the authors proved that $A_{0}$ is contained in the boundary of $A$ in the setting of normed linear spaces.

Definition 1.3 Let $(X, d, \leq)$ be a partially ordered metric space and $A, B$ are nonempty subsets of $X$. A mapping $F: A \times A \rightarrow B$ is said to have proximal mixed monotone property if $F(x, y)$ is proximally nondecreasing in $x$ and is proximally nonincreasing in $y$, that is, for all $x, y \in A$

$$
\left.\begin{array}{l}
x_{1} \leq x_{2}, \\
d\left(u_{1}, F\left(x_{1}, y\right)\right)=d(A, B), \\
d\left(u_{2}, F\left(x_{2}, y\right)\right)=d(A, B)
\end{array}\right\} \quad \Longrightarrow \quad u_{1} \leq u_{2}
$$

and

$$
\begin{aligned}
& \left.\begin{array}{l}
y_{1} \leq y_{2}, \\
d\left(u_{3}, F\left(x, y_{1}\right)\right)=d(A, B), \\
d\left(u_{4}, F\left(x, y_{2}\right)\right)=d(A, B)
\end{array}\right\} \Rightarrow u_{4} \leq u_{3} \\
& \text { where } x_{1}, x_{2}, y_{1}, y_{2}, u_{1}, u_{2}, u_{3}, u_{4} \in A .
\end{aligned}
$$

One can see that, if $A=B$ in the above definition, the notion of the proximal mixed monotone property reduces to that of the mixed monotone property.

Lemma 1.4 Let $(X, d, \leq)$ be a partially ordered metric space and $A, B$ are nonempty subsets of $X$. Assume $A_{0}$ is nonempty. A mapping $F: A \times A \rightarrow B$ has the proximal mixed monotone property with $F\left(A_{0} \times A_{0}\right) \subseteq B_{0}$ whenever $x_{0}, x_{1}, x_{2}, y_{0}, y_{1}$ in $A_{0}$ such that

$$
\left.\begin{array}{c}
x_{0} \leq x_{1} \quad \text { and } \quad y_{0} \geq y_{1}, \\
d\left(x_{1}, F\left(x_{0}, y_{0}\right)\right)=d(A, B), \\
d\left(x_{2}, F\left(x_{1}, y_{1}\right)\right)=d(A, B)
\end{array}\right\} \quad \Longrightarrow \quad x_{1} \leq x_{2} \text {. }
$$


Proof By hypothesis $F\left(A_{0} \times A_{0}\right) \subseteq B_{0}$, therefore $F\left(x_{1}, y_{0}\right) \in B_{0}$. Hence there exists $x_{1}^{*} \in A$ such that

$$
d\left(x_{1}^{*}, F\left(x_{1}, y_{0}\right)\right)=d(A, B) .
$$

Using $F$ is proximal mixed monotone (in particular $F$ is proximally nondecreasing in $x$ ) to (2) and (3), we get

$$
\left.\begin{array}{l}
x_{0} \leq x_{1}, \\
d\left(x_{1}, F\left(x_{0}, y_{0}\right)\right)=d(A, B), \\
d\left(x_{1}^{*}, F\left(x_{1}, y_{0}\right)\right)=d(A, B)
\end{array}\right\} \quad \Longrightarrow \quad x_{1} \leq x_{1}^{*} .
$$

Analogously, using the fact that $F$ is proximal mixed monotone (in particular $F$ is proximally nonincreasing in $y$ ) to (2) and (3), we get

$$
\left.\begin{array}{l}
y_{1} \leq y_{0}, \\
d\left(x_{2}, F\left(x_{1}, y_{1}\right)\right)=d(A, B), \\
d\left(x_{1}^{*}, F\left(x_{1}, y_{0}\right)\right)=d(A, B)
\end{array}\right\} \Rightarrow x_{1}^{*} \leq x_{2} .
$$

From (4) and (5), one can conclude the $x_{1} \leq x_{2}$. Hence the proof.

Lemma 1.5 Let $(X, d, \leq)$ be a partially ordered metric space and $A, B$ are nonempty subsets of $X$. Assume $A_{0}$ is nonempty. A mapping $F: A \times A \rightarrow B$ has proximal mixed monotone property with $F\left(A_{0} \times A_{0}\right) \subseteq B_{0}$ whenever $x_{0}, x_{1}, y_{0}, y_{1}, y_{2}$ in $A_{0}$ such that

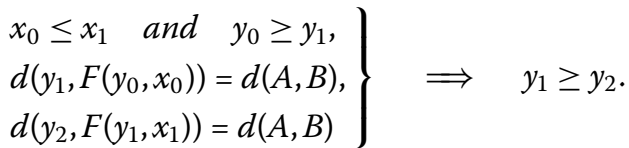

Proof The proof is the same as Lemma 1.4.

Definition 1.6 Let $(X, d, \leq)$ be a partially ordered metric space and $A, B$ are nonempty subsets of $X$. A mapping $F: A \times A \rightarrow B$ is said to be proximally coupled weak $(\psi, \phi)$ contraction on $A$, whenever

$$
\begin{aligned}
& \left.\begin{array}{l}
x_{1} \leq x_{2} \quad \text { and } \quad y_{1} \geq y_{2}, \\
d\left(u_{1}, F\left(x_{1}, y_{1}\right)\right)=d(A, B), \\
d\left(u_{2}, F\left(x_{2}, y_{2}\right)\right)=d(A, B)
\end{array}\right\} \\
& \quad \Longrightarrow \quad \phi\left(d\left(u_{1}, u_{2}\right)\right) \leq \frac{1}{2} \phi\left(d\left(x_{1}, x_{2}\right)+d\left(y_{1}, y_{2}\right)\right)-\psi\left(\frac{d\left(x_{1}, x_{2}\right)+d\left(y_{1}, y_{2}\right)}{2}\right),
\end{aligned}
$$

where $x_{1}, x_{2}, y_{1}, y_{2}, u_{1}, u_{2} \in A$.

One can see that, if $A=B$ in the above definition, the notion of a proximally coupled weak $(\psi, \phi)$ contraction on $A$ reduces to that of a coupled weak $(\psi, \phi)$ contraction. Let us recall the notion of the $P$-property: The pair $(A, B)$ of nonempty subsets of a metric space 
$(X, d)$ with $A_{0} \neq \emptyset$. is said to have the $P$-property if and only if

$$
\left.\begin{array}{l}
d\left(x_{1}, y_{1}\right)=d(A, B), \\
d\left(x_{2}, y_{2}\right)=d(A, B)
\end{array}\right\} \quad \Longrightarrow \quad\left(d\left(x_{1}, x_{2}\right)=d\left(y_{1}, y_{2}\right)\right)
$$

where $x_{1}, x_{2} \in A_{0}$ and $y_{1}, y_{2} \in B_{0}$. It is interesting to note that if the pair $(A, B)$ considered in the above definition has the $P$-property, then the mapping $F$ in Theorem 1.2 satisfies the inequality (1).

\section{Coupled best proximity point theorems}

Let $(X, d, \leq)$ be a partially ordered complete metric space endowed with the product space $X \times X$ with the following partial order:

$$
\text { for }(x, y),(u, v) \in X \times X, \quad(u, v) \leq(x, y) \quad \Longleftrightarrow \quad x \geq u, y \leq v .
$$

Theorem 2.1 Let $(X, \leq, d)$ be a partially ordered complete metric space. Let $A$ and $B$ be nonempty closed subsets of the metric space $(X, d)$ such that $A_{0} \neq \emptyset$. Let $F: A \times A \rightarrow B$ satisfy the following conditions.

(i) $F$ is a continuous proximally coupled weak $(\psi, \phi)$ contraction on $A$ having the proximal mixed monotone property on $A$ such that $F\left(A_{0} \times A_{0}\right) \subseteq B_{0}$.

(ii) There exist elements $\left(x_{0}, y_{0}\right)$ and $\left(x_{1}, y_{1}\right)$ in $A_{0} \times A_{0}$ such that

$$
\begin{aligned}
& d\left(x_{1}, F\left(x_{0}, y_{0}\right)\right)=d(A, B) \quad \text { with } x_{0} \leq x_{1} \quad \text { and } \\
& d\left(y_{1}, F\left(y_{0}, x_{0}\right)\right)=d(A, B) \quad \text { with } y_{0} \geq y_{1} .
\end{aligned}
$$

Then there exists $(x, y) \in A \times A$ such that $d(x, F(x, y))=d(A, B)$ and $d(y, F(y, x))=d(A, B)$.

Proof By hypothesis there exist elements $\left(x_{0}, y_{0}\right)$ and $\left(x_{1}, y_{1}\right)$ in $A_{0} \times A_{0}$ such that

$$
\begin{array}{ll}
d\left(x_{1}, F\left(x_{0}, y_{0}\right)\right)=d(A, B) & \text { with } x_{0} \leq x_{1} \text { and } \\
d\left(y_{1}, F\left(y_{0}, x_{0}\right)\right)=d(A, B) & \text { with } y_{0} \geq y_{1} .
\end{array}
$$

Because of the fact that $F\left(A_{0} \times A_{0}\right) \subseteq B_{0}$, there exists an element $\left(x_{2}, y_{2}\right)$ in $A_{0} \times A_{0}$ such that

$$
\begin{aligned}
& d\left(x_{2}, F\left(x_{1}, y_{1}\right)\right)=d(A, B) \quad \text { and } \\
& d\left(y_{2}, F\left(y_{1}, x_{1}\right)\right)=d(A, B) .
\end{aligned}
$$

Hence from Lemma 1.4 and Lemma 1.5, we obtain $x_{1} \leq x_{2}$ and $y_{1} \geq y_{2}$.

Continuing this process, we can construct the sequences $\left(x_{n}\right)$ and $\left(y_{n}\right)$ in $A_{0}$ such that

$$
d\left(x_{n+1}, F\left(x_{n}, y_{n}\right)\right)=d(A, B), \quad \forall n \in \mathbb{N} \text { with } x_{0} \leq x_{1} \leq x_{2} \leq \cdots \leq x_{n} \leq x_{n+1} \leq \cdots
$$

and

$$
d\left(y_{n+1}, F\left(y_{n}, x_{n}\right)\right)=d(A, B), \quad \forall n \in \mathbb{N} \text { with } y_{0} \geq y_{1} \geq y_{2} \geq \cdots \geq y_{n} \geq y_{n+1} \geq \cdots
$$

Then $d\left(x_{n}, F\left(x_{n-1}, y_{n-1}\right)\right)=d(A, B), d\left(x_{n+1}, F\left(x_{n}, y_{n}\right)\right)=d(A, B)$ and also we have $x_{n-1} \leq x_{n}$, $y_{n-1} \geq y_{n}, \forall n \in \mathbb{N}$. Now using the fact that $F$ is a proximally coupled weak $(\psi, \phi)$ contrac- 
tion on $A$ we get

$$
\begin{aligned}
\phi\left(d\left(x_{n}, x_{n+1}\right)\right) \leq & \frac{1}{2} \phi\left(d\left(x_{n-1}, x_{n}\right)+d\left(y_{n-1}, y_{n}\right)\right) \\
& -\psi\left(\frac{d\left(x_{n-1}, x_{n}\right)+d\left(y_{n-1}, y_{n}\right)}{2}\right), \quad \forall n \in \mathbb{N} .
\end{aligned}
$$

Similarly

$$
\begin{aligned}
\phi\left(d\left(y_{n}, y_{n+1}\right)\right) \leq & \frac{1}{2} \phi\left(d\left(y_{n-1}, y_{n}\right)+d\left(x_{n-1}, x_{n}\right)\right) \\
& -\psi\left(\frac{d\left(y_{n-1}, y_{n}\right)+d\left(x_{n-1}, x_{n}\right)}{2}\right), \quad \forall n \in \mathbb{N} .
\end{aligned}
$$

Adding (11) and (12), we get

$$
\begin{aligned}
\phi\left(d\left(x_{n}, x_{n+1}\right)\right)+\phi\left(d\left(y_{n}, y_{n+1}\right)\right) \leq & \phi\left(d\left(x_{n-1}, x_{n}\right)+d\left(y_{n-1}, y_{n}\right)\right) \\
& -2 \psi\left(\frac{d\left(x_{n-1}, x_{n}\right)+d\left(y_{n-1}, y_{n}\right)}{2}\right) .
\end{aligned}
$$

By the property (iii) of $\phi$ we have

$$
\phi\left(d\left(x_{n}, x_{n+1}\right)+d\left(y_{n}, y_{n+1}\right)\right) \leq \phi\left(d\left(x_{n}, x_{n+1}\right)\right)+\phi\left(d\left(y_{n}, y_{n+1}\right)\right) .
$$

From (13) and (14), we get

$$
\begin{aligned}
\phi\left(d\left(x_{n}, x_{n+1}\right)+d\left(y_{n}, y_{n+1}\right)\right) \leq & \phi\left(d\left(x_{n-1}, x_{n}\right)+d\left(y_{n-1}, y_{n}\right)\right) \\
& -2 \psi\left(\frac{d\left(x_{n-1}, x_{n}\right)+d\left(y_{n-1}, y_{n}\right)}{2}\right) .
\end{aligned}
$$

Using the fact that $\phi$ is nondecreasing, we get

$$
d\left(x_{n}, x_{n+1}\right)+d\left(y_{n}, y_{n+1}\right) \leq d\left(x_{n-1}, x_{n}\right)+d\left(y_{n-1}, y_{n}\right)
$$

Set $\delta_{n}=d\left(x_{n}, x_{n+1}\right)+d\left(y_{n}, y_{n+1}\right)$; then the sequence $\left(\delta_{n}\right)$ is decreasing. Therefore, there is some $\delta \geq 0$ such that

$$
\lim _{n \rightarrow \infty} \delta_{n}=\lim _{n \rightarrow \infty}\left[d\left(x_{n}, x_{n+1}\right)+d\left(y_{n}, y_{n+1}\right)\right]=\delta
$$

We shall show that $\delta=0$. Suppose, to the contrary, that $\delta>0$. Then taking the limit as $n \rightarrow \infty$ on both sides of (15) and having in mind that we assume $\lim _{t \rightarrow r} \psi(t)>0$ for all $r>0$ and $\phi$ is continuous, we have

$$
\phi(\delta)=\lim _{n \rightarrow \infty} \phi\left(\delta_{n}\right) \leq \lim _{n \rightarrow \infty} \phi\left(\delta_{n-1}\right)-2 \psi\left(\frac{\delta_{n-1}}{2}\right)=\phi(\delta)-2 \lim _{n \rightarrow \infty} \psi\left(\frac{\delta_{n-1}}{2}\right)<\phi(\delta),
$$

a contradiction. Thus $\delta=0$, that is,

$$
\lim _{n \rightarrow \infty} \delta_{n}=\lim _{n \rightarrow \infty}\left[d\left(x_{n+1}, x_{n}\right)+d\left(y_{n+1}, y_{n}\right)\right]=0 .
$$


Now we prove that $\left(x_{n}\right)$ and $\left(y_{n}\right)$ are Cauchy sequences. Assume that at least one of the sequences $\left(x_{n}\right)$ or $\left(y_{n}\right)$ is not a Cauchy sequence. This implies that $\lim _{n, m \rightarrow \infty} d\left(x_{n}, x_{m}\right) \nrightarrow 0$ or $\lim _{n, m \rightarrow \infty} d\left(y_{n}, y_{m}\right) \nrightarrow 0$, and, consequently,

$$
\lim _{n, m \rightarrow \infty}\left[d\left(x_{n}, x_{m}\right)+d\left(y_{n}, y_{m}\right)\right] \nrightarrow 0 .
$$

Then there exists $\epsilon>0$ for which we can find subsequences $\left(x_{n(k)}\right),\left(x_{m(k)}\right)$ of $\left(x_{n}\right)$ and $\left(y_{n(k)}\right)$, $\left(y_{m(k)}\right)$ of $\left(y_{n}\right)$ such that $n(k)$ is the smallest index for which $n(k)>m(k)>k$,

$$
\left[d\left(x_{n(k)}, x_{m(k)}\right)+d\left(y_{n(k)}, y_{m(k)}\right)\right] \geq \epsilon .
$$

This means that

$$
d\left(x_{n(k)-1}, x_{m(k)}\right)+d\left(y_{n(k)-1}, y_{m(k)}\right)<\epsilon .
$$

Using (19), (20), and the triangle inequality, we have

$$
\begin{aligned}
\epsilon & \leq r_{k}:=d\left(x_{n(k)}, x_{m(k)}\right)+d\left(y_{n(k)}, y_{m(k)}\right) \\
& \leq d\left(x_{n(k)}, x_{n(k)-1}\right)+d\left(x_{n(k)-1}, x_{m(k)}\right)+d\left(y_{n(k)}, y_{n(k)-1}\right)+d\left(y_{n(k)-1}, y_{m(k)}\right) \\
& \leq d\left(x_{n(k)}, x_{n(k)-1}\right)+d\left(y_{n(k)}, y_{n(k)-1}\right)+\epsilon .
\end{aligned}
$$

Letting $k \rightarrow \infty$ and using (18), we obtain

$$
\lim _{k \rightarrow \infty} r_{k}=\lim _{k \rightarrow \infty}\left[d\left(x_{n(k)}, x_{m(k)}\right)+d\left(y_{n(k)}, y_{m(k)}\right)\right]=\epsilon .
$$

By the triangle inequality

$$
\begin{aligned}
r_{k}= & d\left(x_{n(k)}, x_{m(k)}\right)+d\left(y_{n(k)}, y_{m(k)}\right) \\
\leq & d\left(x_{n(k)}, x_{n(k)+1}\right)+d\left(x_{n(k)+1}, x_{m(k)+1}\right)+d\left(x_{m(k)+1}, x_{m(k)}\right) \\
& +d\left(y_{n(k)}, y_{n(k)+1}\right)+d\left(y_{n(k)+1}, y_{m(k)+1}\right)+d\left(y_{m(k)+1}, y_{m(k)}\right) \\
= & \delta_{n(k)}+\delta_{m(k)}+d\left(x_{n(k)+1}, x_{m(k)+1}\right)+d\left(y_{n(k)+1}, y_{m(k)+1}\right) .
\end{aligned}
$$

Using the property of $\phi$, we obtain

$$
\begin{aligned}
\phi\left(r_{k}\right) & =\phi\left(\delta_{n(k)}+\delta_{m(k)}+d\left(x_{n(k)+1}, x_{m(k)+1}\right)+d\left(y_{n(k)+1}, y_{m(k)+1}\right)\right) \\
& \leq \phi\left(\delta_{n(k)}\right)+\phi\left(\delta_{m(k)}\right)+\phi\left(d\left(x_{n(k)+1}, x_{m(k)+1}\right)\right)+\phi\left(d\left(y_{n(k)+1}, y_{m(k)+1}\right)\right) .
\end{aligned}
$$

Since $x_{n(k)} \geq x_{m(k)}$ and $y_{n(k)} \leq y_{m(k)}$, using the fact that $F$ is a proximally coupled weak $(\psi, \phi)$ contraction on $A$ we get

$$
\begin{aligned}
\phi\left(d\left(x_{n(k)+1}, x_{m(k)+1}\right)\right) \leq & \frac{1}{2} \phi\left(d\left(x_{n(k)}, x_{m(k)}\right)+d\left(y_{n(k)}, y_{m(k)}\right)\right) \\
& -\psi\left(\frac{d\left(x_{n(k)}, x_{m(k)}\right)+d\left(y_{n(k)}, y_{m(k)}\right)}{2}\right) \\
\leq & \frac{1}{2} \phi\left(r_{k}\right)-\psi\left(\frac{r_{k}}{2}\right) .
\end{aligned}
$$


Similarly, we also have

$$
\begin{aligned}
\phi\left(d\left(y_{m(k)+1}, y_{n(k)+1}\right)\right) \leq & \frac{1}{2} \phi\left(d\left(y_{m(k)}, y_{n(k)}\right)+d\left(x_{m(k)}, x_{n(k)}\right)\right) \\
& -\psi\left(\frac{d\left(y_{m(k)}, y_{n(k)}\right)+d\left(x_{m(k)}, x_{n(k)}\right)}{2}\right) \\
\leq & \frac{1}{2} \phi\left(r_{k}\right)-\psi\left(\frac{r_{k}}{2}\right) .
\end{aligned}
$$

From (22)-(24), we have

$$
\phi\left(r_{k}\right) \leq \phi\left(\delta_{n(k)}+\delta_{m(k)}\right)+\phi\left(r_{k}\right)-2 \psi\left(\frac{r_{k}}{2}\right) .
$$

Letting $k \rightarrow \infty$ and using (18) and (21), we have

$$
\phi(\epsilon) \leq \phi(0)+\phi(\epsilon)-2 \lim _{k \rightarrow \infty} \psi\left(\frac{r_{k}}{2}\right)=\phi(\epsilon)-2 \lim _{k \rightarrow \infty} \psi\left(\frac{r_{k}}{2}\right)<\phi(\epsilon)
$$

a contradiction. This shows that $\left(x_{n}\right)$ and $\left(y_{n}\right)$ are Cauchy sequences. Since $A$ is a closed subset of a complete metric space $X$, these sequences have limits. Thus, there exist $x, y \in A$ such that $x_{n} \rightarrow x$ and $y_{n} \rightarrow y$. Therefore $\left(x_{n}, y_{n}\right) \rightarrow(x, y)$ in $A \times A$. Since $F$ is continuous, we have $F\left(x_{n}, y_{n}\right) \rightarrow F(x, y)$ and $F\left(y_{n}, x_{n}\right) \rightarrow F(y, x)$.

Hence the continuity of the metric function $d$ implies that $d\left(x_{n+1}, F\left(x_{n}, y_{n}\right)\right) \rightarrow d(x$, $F(x, y))$ and $d\left(y_{n+1}, F\left(y_{n}, x_{n}\right)\right) \rightarrow d(y, F(y, x))$. But from (9) and (10) we see that the sequences $\left(d\left(x_{n+1}, F\left(x_{n}, y_{n}\right)\right)\right)$ and $\left(d\left(y_{n+1}, F\left(y_{n}, x_{n}\right)\right)\right)$ are constant sequences with the value $d(A, B)$. Therefore, $d(x, F(x, y))=d(A, B)$ and $d(y, F(y, x))=d(A, B)$. This completes the proof of the theorem.

Corollary 2.1 Let $(X, \leq, d)$ be a partially ordered complete metric space. Let $A$ be nonempty closed subsets of the metric space $(X, d)$. Let $F: A \times A \rightarrow A$ satisfy the following conditions.

(i) $F$ is continuous having the proximal mixed monotone property and proximally coupled weak $(\psi, \phi)$ contraction on $A$.

(ii) There exist $\left(x_{0}, y_{0}\right)$ and $\left(x_{1}, y_{1}\right)$ in $A \times A$ such that $x_{1}=F\left(x_{0}, y_{0}\right)$ with $x_{0} \leq x_{1}$ and $y_{1}=F\left(y_{0}, x_{0}\right)$ with $y_{0} \geq y_{1}$.

Then there exists $(x, y) \in A \times A$ such that $d(x, F(x, y))=0$ and $d(y, F(y, x))=0$.

In what follows we prove that Theorem 2.1 is still valid for $F$ not necessarily continuous, assuming the following hypotheses in $A$. $A$ has the property that

$\left(x_{n}\right)$ is a nondecreasing sequence in $A$ such that $x_{n} \rightarrow x$; then $x_{n} \leq x$,

$\left(y_{n}\right)$ is a nonincreasing sequence in $A$ such that $y_{n} \rightarrow y$; then $y \leq y_{n}$.

Theorem 2.2 Assume the conditions (25), (26) and $A_{0}$ is closed in $X$ instead of continuity of $F$ in Theorem 2.1, then the conclusion of Theorem 2.1 holds. 
Proof Following the proof of Theorem 2.1, there exist sequences $\left(x_{n}\right)$ and $\left(y_{n}\right)$ in $A$ satisfying the following conditions:

$$
\begin{array}{ll}
d\left(x_{n+1}, F\left(x_{n}, y_{n}\right)\right)=d(A, B) & \text { with } x_{n} \leq x_{n+1}, \forall n \in \mathbb{N} \text { and } \\
d\left(y_{n+1}, F\left(y_{n}, x_{n}\right)\right)=d(A, B) & \text { with } y_{n} \geq y_{n+1}, \forall n \in \mathbb{N} .
\end{array}
$$

Moreover, $x_{n}$ converges to $x$ and $y_{n}$ converges to $y$ in $A$. From (25) and (26), we get $x_{n} \leq x$ and $y_{n} \geq y$. Note that the sequences $\left(x_{n}\right)$ and $\left(y_{n}\right)$ are in $A_{0}$ and $A_{0}$ is closed. Therefore, $(x, y) \in A_{0} \times A_{0}$. Since $F\left(A_{0} \times A_{0}\right) \subseteq B_{0}$, there exist $F(x, y)$ and $F(y, x)$ in $B_{0}$. Therefore, there exists $\left(x^{*}, y^{*}\right) \in A_{0} \times A_{0}$ such that

$$
\begin{aligned}
& d\left(x^{*}, F(x, y)\right)=d(A, B) \quad \text { and } \\
& d\left(y^{*}, F(y, x)\right)=d(A, B) .
\end{aligned}
$$

Since $x_{n} \leq x$ and $y_{n} \geq y$. By using the fact that $F$ is a proximally coupled weak $(\psi, \phi)$ contraction on $A$ for (27) and (29), and also for (30) and (28), we get

$$
\begin{array}{ll}
\phi\left(d\left(x_{n+1}, x^{*}\right)\right) \leq \frac{1}{2} \phi\left(d\left(x_{n}, x\right)+d\left(y_{n}, y\right)\right)-\psi\left(\frac{d\left(x_{n}, x\right)+d\left(y_{n}, y\right)}{2}\right) & \text { for all } n \text { and } \\
\phi\left(d\left(y^{*}, y_{n+1}\right)\right) \leq \frac{1}{2} \phi\left(d\left(y, y_{n}\right)+d\left(x, x_{n}\right)\right)-\psi\left(\frac{d\left(y, y_{n}\right)+d\left(x, x_{n}\right)}{2}\right) & \text { for all } n .
\end{array}
$$

Since $x_{n} \rightarrow x$ and $y_{n} \rightarrow y$, by taking the limit on the above two inequalities, we get $x=$ $x^{*}$ and $y=y^{*}$. Hence, from (29) and (30), we get $d(x, F(x, y))=d(A, B)$ and $d(y, F(y, x))=$ $d(A, B)$.

Corollary 2.2 Assume the conditions (25) and (26) instead of continuity of F in Corollary 2.1, then the conclusion of Corollary 2.1 holds.

Now, we present an example where it can be appreciated that the hypotheses in Theorem 2.1 and Theorem 2.2 do not guarantee uniqueness of the coupled best proximity point.

Example 2.3 Let $X=\{(0,1),(1,0),(-1,0),(0,-1)\} \subset \mathbb{R}^{2}$ and consider the usual order $(x, y) \preceq(z, t) \Leftrightarrow x \leq z$ and $y \leq t$.

Thus, $(X, \preceq)$ is a partially ordered set. Besides, $\left(X, d_{2}\right)$ is a complete metric space considering $d_{2}$ the Euclidean metric. Let $A=\{(0,1),(1,0)\}$ and $B=\{(0,-1),(-1,0)\}$ be a closed subset of $X$. Then $d(A, B)=\sqrt{2}, A=A_{0}$ and $B=B_{0}$. Let $F: A \times A \rightarrow B$ be defined as $F\left(\left(x_{1}, x_{2}\right),\left(y_{1}, y_{2}\right)\right)=\left(-x_{2},-x_{1}\right)$. Then, it can be seen that $F$ is continuous such that $F\left(A_{0} \times A_{0}\right) \subseteq B_{0}$. The only comparable pairs of points in $A$ are $x \preceq x$ for $x \in A$, hence the proximal mixed monotone property and the proximally coupled weak $(\psi, \phi)$ contraction on $A$ are satisfied trivially.

It can be shown that the other hypotheses of the theorem are also satisfied. However, $F$ has three coupled best proximity points, $((0,1),(0,1)),((0,1),(1,0))$, and $((1,0),(1,0))$.

One can prove that the coupled best proximity point is in fact unique, provided that the product space $A \times A$ endowed with the partial order mentioned earlier has the following 
property:

Every pair of elements has either a lower bound or an upper bound.

It is known that this condition is equivalent to the following.

For every pair of $(x, y),\left(x^{*}, y^{*}\right) \in A \times A$, there exists $\left(z_{1}, z_{2}\right)$ in $A \times A$

that is comparable to $(x, y)$ and $\left(x^{*}, y^{*}\right)$.

Theorem 2.4 In addition to the hypothesis of Theorem 2.1 (resp. Theorem 2.2), suppose that for any two elements $(x, y)$ and $\left(x^{*}, y^{*}\right)$ in $A_{0} \times A_{0}$,

there exists $\left(z_{1}, z_{2}\right) \in A_{0} \times A_{0}$ such that

$\left(z_{1}, z_{2}\right)$ is comparable to $(x, y)$ and $\left(x^{*}, y^{*}\right)$,

then $F$ has a unique coupled best proximity point.

Proof From Theorem 2.1 (resp. Theorem 2.2), the set of coupled best proximity points of $F$ is nonempty. Suppose that there exist $(x, y)$ and $\left(x^{*}, y^{*}\right)$ in $A \times A$ which are coupled best proximity points. That is,

$$
\begin{aligned}
& d(x, F(x, y))=d(A, B), d(y, F(y, x))=d(A, B) \quad \text { and } \\
& d\left(x^{*}, F\left(x^{*}, y^{*}\right)\right)=d(A, B), d\left(y^{*}, F\left(y^{*}, x^{*}\right)\right)=d(A, B) .
\end{aligned}
$$

We distinguish two cases.

Case 1: Suppose $(x, y)$ is comparable. Let $(x, y)$ is comparable to $\left(x^{*}, y^{*}\right)$ with respect to the ordering in $A \times A$. Applying the fact that $F$ is a proximally coupled weak $(\psi, \phi)$ contraction on $A$ to $d(x, F(x, y))=d(A, B)$ and $d\left(x^{*}, F\left(x^{*}, y^{*}\right)\right)=d(A, B)$, we get

$$
\phi\left(d\left(x, x^{*}\right)\right) \leq \frac{1}{2} \phi\left(d\left(x, x^{*}\right)+d\left(y, y^{*}\right)\right)-\psi\left(\frac{d\left(x, x^{*}\right)+d\left(y, y^{*}\right)}{2}\right) .
$$

Similarly, one can prove that

$$
\phi\left(d\left(y, y^{*}\right)\right) \leq \frac{1}{2} \phi\left(d\left(y, y^{*}\right)+d\left(x, x^{*}\right)\right)-\psi\left(\frac{d\left(y, y^{*}\right)+d\left(x, x^{*}\right)}{2}\right) .
$$

Adding (34) and (35), we get

$$
\phi\left(d\left(x, x^{*}\right)\right)+\phi\left(d\left(y, y^{*}\right)\right) \leq \phi\left(d\left(x, x^{*}\right)+d\left(y, y^{*}\right)\right)-2 \psi\left(\frac{d\left(x, x^{*}\right)+d\left(y, y^{*}\right)}{2}\right) .
$$

By the property (iii) of $\phi$, we have

$$
\phi\left(d\left(x, x^{*}\right)+d\left(y, y^{*}\right)\right) \leq \phi\left(d\left(x, x^{*}\right)\right)+\phi\left(d\left(y, y^{*}\right)\right) .
$$

From (36) and (37), we have

$$
\phi\left(d\left(x, x^{*}\right)\right)+\phi\left(d\left(y, y^{*}\right)\right) \leq \phi\left(d\left(x, x^{*}\right)\right)+\phi\left(d\left(y, y^{*}\right)\right)-2 \psi\left(\frac{d\left(x, x^{*}\right)+d\left(y, y^{*}\right)}{2}\right) ;
$$


this implies that $2 \psi\left(\frac{d\left(x, x^{*}\right)+d\left(y, y^{*}\right)}{2}\right) \leq 0$, and using the property of $\psi$, we get $d\left(x, x^{*}\right)+$ $d\left(y, y^{*}\right)=0$, hence $x=x^{*}$ and $y=y^{*}$.

Case 2: Suppose $(x, y)$ is not comparable. Let $(x, y)$ be not comparable to $\left(x^{*}, y^{*}\right)$, then there exists $\left(u_{1}, v_{1}\right) \in A_{0} \times A_{0}$ which is comparable to $(x, y)$ and $\left(x^{*}, y^{*}\right)$.

Since $F\left(A_{0} \times A_{0}\right) \subseteq B_{0}$, there exists $\left(u_{2}, v_{2}\right) \in A_{0} \times A_{0}$ such that $d\left(u_{2}, F\left(u_{1}, v_{1}\right)\right)=d(A, B)$ and $d\left(v_{2}, F\left(v_{1}, u_{1}\right)\right)=d(A, B)$. Without loss of generality assume that $\left(u_{1}, v_{1}\right) \leq(x, y)$ (i.e., $x \geq u_{1}$ and $\left.y \leq v_{1}\right)$. Note that $\left(u_{1}, v_{1}\right) \leq(x, y)$ implies that $(y, x) \leq\left(v_{1}, u_{1}\right)$. From Lemma 1.4 and Lemma 1.5, we get

$$
\left.\begin{array}{l}
u_{1} \leq x \quad \text { and } \quad v_{1} \geq y, \\
d\left(u_{2}, F\left(u_{1}, v_{1}\right)\right)=d(A, B), \\
d(x, F(x, y))=d(A, B)
\end{array}\right\} \quad \Longrightarrow \quad u_{2} \leq x
$$

and

$$
\left.\begin{array}{l}
u_{1} \leq x \quad \text { and } \quad v_{1} \geq y, \\
d\left(v_{2}, F\left(v_{1}, u_{1}\right)\right)=d(A, B), \\
d(y, F(y, x))=d(A, B)
\end{array}\right\} \quad \Longrightarrow \quad v_{2} \geq y \text {. }
$$

From the above two inequalities, we obtain $\left(u_{2}, v_{2}\right) \leq(x, y)$. Continuing this process, we get sequences $\left(u_{n}\right)$ and $\left(v_{n}\right)$ such that $d\left(u_{n+1}, F\left(u_{n}, v_{n}\right)\right)=d(A, B)$ and $d\left(v_{n+1}, F\left(v_{n}, u_{n}\right)\right)=d(A, B)$ with $\left(u_{n}, v_{n}\right) \leq(x, y), \forall n \in \mathbb{N}$. By using the fact that $F$ is a proximally coupled weak $(\psi, \phi)$ contraction on $A$, we get

$$
\begin{aligned}
& \left.\begin{array}{l}
u_{n} \leq x \quad \text { and } \quad v_{n} \geq y, \\
d\left(u_{n+1}, F\left(u_{n}, v_{n}\right)\right)=d(A, B), \\
d(x, F(x, y))=d(A, B)
\end{array}\right\} \\
& \quad \Longrightarrow \quad \phi\left(d\left(u_{n+1}, x\right)\right) \leq \frac{1}{2} \phi\left(d\left(u_{n}, x\right)+d\left(v_{n}, y\right)\right)-\psi\left(\frac{d\left(u_{n}, x\right)+d\left(v_{n}, y\right)}{2}\right) .
\end{aligned}
$$

Similarly, we can prove that

$$
\begin{aligned}
& \left.\begin{array}{l}
y \leq v_{n} \quad \text { and } \quad x \geq u_{n}, \\
d(y, F(y, x))=d(A, B), \\
d\left(v_{n+1}, F\left(v_{n}, u_{n}\right)\right)=d(A, B)
\end{array}\right\} \\
& \quad \Longrightarrow \quad \phi\left(d\left(y, v_{n+1}\right)\right) \leq \frac{1}{2} \phi\left(d\left(y, v_{n}\right)+d\left(x, u_{n}\right)\right)-\psi\left(\frac{d\left(y, v_{n}\right)+d\left(x, u_{n}\right)}{2}\right) .
\end{aligned}
$$

Adding (39) and (40), we obtain

$$
\phi\left(d\left(u_{n+1}, x\right)\right)+\phi\left(d\left(y, v_{n+1}\right)\right) \leq \phi\left(d\left(u_{n}, x\right)+d\left(v_{n}, y\right)\right)-2 \psi\left(\frac{d\left(u_{n}, x\right)+d\left(v_{n}, y\right)}{2}\right) .
$$

$\operatorname{But} \phi\left(d\left(u_{n+1}, x\right)+d\left(y, v_{n+1}\right)\right) \leq \phi\left(d\left(u_{n+1}, x\right)\right)+\phi\left(d\left(y, v_{n+1}\right)\right)$, hence

$$
\begin{aligned}
\phi\left(d\left(u_{n+1}, x\right)+d\left(y, v_{n+1}\right)\right) & \leq \phi\left(d\left(u_{n}, x\right)+d\left(v_{n}, y\right)\right)-2 \psi\left(\frac{d\left(u_{n}, x\right)+d\left(v_{n}, y\right)}{2}\right) \\
& \leq \phi\left(d\left(u_{n}, x\right)+d\left(v_{n}, y\right)\right) .
\end{aligned}
$$


Using the fact that $\phi$ is nondecreasing, we get

$$
d\left(u_{n+1}, x\right)+d\left(y, v_{n+1}\right) \leq d\left(u_{n}, x\right)+d\left(v_{n}, y\right) .
$$

That is, the sequence $\left(d\left(u_{n}, x\right)+d\left(y, v_{n}\right)\right)$ is decreasing. Therefore, there exists $\alpha \geq 0$ such that

$$
\lim _{n \rightarrow \infty}\left[d\left(u_{n}, x\right)+d\left(y, v_{n}\right)\right]=\alpha .
$$

We shall show that $\alpha=0$. Suppose, to the contrary, that $\alpha>0$. Taking the limit as $n \rightarrow \infty$ in (42), we have

$$
\phi(\alpha) \leq \phi(\alpha)-2 \lim _{n \rightarrow \infty} \psi\left(\frac{d\left(u_{n}, x\right)+d\left(v_{n}, y\right)}{2}\right)<\phi(\alpha),
$$

a contradiction. Thus, $\alpha=0$, that is,

$$
\lim _{n \rightarrow \infty}\left[d\left(u_{n}, x\right)+d\left(y, v_{n}\right)\right]=0
$$

so that $u_{n} \rightarrow x$ and $v_{n} \rightarrow y$. Analogously, one can prove that $u_{n} \rightarrow x^{*}$ and $v_{n} \rightarrow y^{*}$.

Therefore, $x=x^{*}$ and $y=y^{*}$. Hence the proof.

The following result, due to Theorem 2.4 in Luong and Thuan [25] follows by taking $A=B$.

Corollary 2.3 In addition to the hypothesis of Corollary 2.1 (resp. Corollary 2.2), suppose that for any two elements $(x, y)$ and $\left(x^{*}, y^{*}\right)$ in $A \times A$,

there exists $\left(z_{1}, z_{2}\right) \in A \times A$ such that $\left(z_{1}, z_{2}\right)$ is comparable to $(x, y)$ and $\left(x^{*}, y^{*}\right)$,

then $F$ has a unique coupled fixed point.

Competing interests

The authors declare that they have no competing interests.

Authors' contributions

The main idea of this paper was proposed by PK, VP, MM and KS prepared the manuscript initially and performed all the steps of the proofs in this research. All authors read and approved the final manuscript.

\section{Author details}

'Department of Mathematics, Faculty of Science, King Mongkut's University of Technology Thonburi (KMUTT), Bang Mod, Thrung Khru, Bangkok, 10140, Thailand. ${ }^{2}$ Department of Mathematics, Bharathidasan University, Tiruchirappalli, Tamil Nadu 620 024, India. ${ }^{3}$ Nonlinear Dynamic Analysis Research Center, Department of Mathematics, Faculty of Applied Science, King Mongkut's University of North Bangkok (KMUTNB), Wongsawang, Bangsue, Bangkok, 10800, Thailand.

\section{Acknowledgements}

The first author was supported by the Higher Education Research Promotion and National Research University Project of Thailand, Office of the Higher Education Commission (NRU2557). Moreover, Kanokwan Sitthithakerngkiet would like to thank the King Mongkut's University of Technology North Bangkok for financial support. 


\section{References}

1. Fan, K: Extensions of two fixed point theorems of F.E. Browder. Math. Z. 122, 234-240 (1969)

2. Abkar, A, Gabeleh, M: Best proximity points for cyclic mappings in ordered metric spaces. J. Optim. Theory Appl. 150(1), 188-193 (2011)

3. De la Sen, M, Agarwal, RP: Some fixed point-type results for a class of extended cyclic self-mappings with a more general contractive condition. Fixed Point Theory Appl. 2011, 59 (2011)

4. Srinivasan, PS, Veeramani, P: On existence of equilibrium pair for constrained generalized games. Fixed Point Theory Appl. 1, 21-29 (2004)

5. Eldred, AA, Veeramani, P: Existence and convergence of best proximity points. J. Math. Anal. Appl. 323, 1001-1006 (2006)

6. Al-Thagafi, MA, Shahzad, N: Convergence and existence results for best proximity points. Nonlinear Anal. 70, 3665-3671 (2009)

7. Sadiq Basha, S, Veeramani, P: Best proximity pair theorems for multifunctions with open fibres. J. Approx. Theory 103, 119-129 (2000)

8. Kim, WK, Lee, KH: Existence of best proximity pairs and equilibrium pairs. J. Math. Anal. Appl. 316(2), $433-446$ (2006)

9. Kirk, WA, Reich, S, Veeramani, P: Proximinal retracts and best proximity pair theorems. Numer. Funct. Anal. Optim. 24 851-862 (2003)

10. Sankar Raj, V: A best proximity point theorem for weakly contractive non-self-mappings. Nonlinear Anal. 74 4804-4808 (2011)

11. Kumam, P, Aydi, H, Karapinar, E, Sintunavarat, W: Best proximity points and extension of Mizoguchi-Takahashi's fixed point theorems. Fixed Point Theory Appl. 2013, 242 (2013)

12. Sintunavarat, W, Kumam, P: The existence theorems of an optimal approximate solution for generalized proxima contraction mappings. Abstr. Appl. Anal. 2013, Article ID 375604 (2013)

13. Karapinar, E, Sintunavarat, W: The existence of an optimal approximate solution theorems for generalized $\alpha$-proxima contraction nonself mappings and applications. Fixed Point Theory Appl. 2013, 323 (2013)

14. Sadiq Basha, S: Discrete optimization in partially ordered sets. J. Glob. Optim. (2011). doi:10.1007/s10898-011-9774-2

15. Abkar, A, Gabeleh, M: Generalized cyclic contractions in partially ordered metric spaces. Optim. Lett. (2011). doi:10.1007/s11590-011-0379-y

16. Sintunavarat, W, Kumam, P: Coupled best proximity point theorem in metric spaces. Fixed Point Theory Appl. 2012, 93 (2012)

17. Pragadeeswarar, $V$, Marudai, M: Best proximity points: approximation and optimization in partially ordered metric spaces. Optim. Lett. (2012). doi:10.1007/s11590-012-0529-x

18. Bhaskar, TG, Lakshmikantham, V: Fixed point theorems in partially ordered metric spaces and applications. Nonlinear Anal. 65, 1379-1393 (2006)

19. Lakshmikantham, V, Ćirić, L: Coupled fixed point theorems for nonlinear contractions in partially ordered metric spaces. Nonlinear Anal. 70(12), 4341-4349 (2009)

20. Luong, BV, Thuan, NX: Coupled fixed point theorems for mixed monotone mappings and an application to integral equations. Comput. Math. Appl. 62(11), 4238-4248 (2011)

21. Shatanawi, W: Partially ordered metric spaces and coupled fixed point results. Comput. Math. Appl. 60, 2508-2515 (2010)

22. Hussain, N, Abbas, M, Azam, A, Ahmad, J: Coupled coincidence point results for a generalized compatible pair with applications. Fixed Point Theory Appl. 2014, 62 (2014)

23. Kutbi, MA, Azam, A, Ahmad, J, Di Bari, C: Some common coupled fixed point results for generalized contraction in complex-valued metric spaces. J. Appl. Math. 2013, Article ID 352927 (2013)

24. Jleli, M, Samet, B: Remarks on the paper: Best proximity point theorems: an exploration of a common solution to approximation and optimization problems. Appl. Math. Comput. 228, 366-370 (2014)

25. Luong, BV, Thuan, NX: Coupled fixed points in partially ordered metric spaces and application. Nonlinear Anal. 74 983-992 (2011)

10.1186/1687-1812-2014-107

Cite this article as: Kumam et al.: Coupled best proximity points in ordered metric spaces. Fixed Point Theory and Applications 2014, 2014:107

\section{Submit your manuscript to a SpringerOpen ${ }^{\circ}$ journal and benefit from:}

- Convenient online submission

- Rigorous peer review

- Immediate publication on acceptance

- Open access: articles freely available online

- High visibility within the field

- Retaining the copyright to your article 